Nordisk Tidsskrift for Kriminalvidenskab 2010

\title{
HUR SÄKERSTÄLLER VI EN ENHETLIG PÅFÖLJDSBESTÄMNING?
}

\section{Av hovrättSlagman Martin BorgeKe*}

The author emphasizes the importance of the principle of legality when establishing the penalty for a crime. He describes how to achieve greater coherence and presents his views on the responsibilities of different authorities and actors. While the author sees the Swedish courts as fairly consistent, he argues that much more could be done to ensure equal penalties in equal cases. He highlights the Supreme Court's responsibilities and the need to continually examine the quality of judicial work. The potential advantages of using computer-assisted techniques to harmonize crime penalties are explored. $* *$

\section{Legalitetsprincipen}

Legalitetsprincipen innebär att ingen får straffas om inte det som han eller hon har gjort var kriminaliserat när gärningen utfördes. Legalitetsprincipen, som är av grundläggande betydelse och är en förutsättning för att ett land ska kunna betraktas som en rättsstat, utformades av upplysningstidens filosofer. Sitt första auktoritativa uttryck fick den i franska revolutionens rättighetsförklaring år 1789.

Legalitetsprincipen utgjorde en reaktion mot det godtycke som rådde inom domstolarna. Den ingår numera som en väsentlig del i de civiliserade ländernas rättssystem. I svensk rätt har den respekterats i ungefär 200 år. Dess mest kända formulering gavs av den tyske straffrättsreformatorn Anselm von Feuerbach ${ }^{1}$, som i början av 1800-talet definierade den med satserna: nulla poena sine lege, nulla poena sine crimine, nullum crimen sine poena legali dvs. inget straff utan lag, inget straff utan brott, inget brott utan kriminalisering genom lag.

Vi vet att inte alla stater lever upp till de krav som legalitetsprincipen ställer på lagstiftningen och på rättstillämpningen. Men hos oss i västerlandet respekteras den och det inte bara på straffrättens område. Även på andra fält är den viktig, t.ex. inom skattelagstiftningen. Här kommer dock bara dess betydelse för straffrätten att diskuteras.

Legalitetsprincipen har i Sverige grundlagsstöd i 2 kap. $10 \S$ regeringsformen. På grund av dess betydelse inom straffrätten tas den dessutom upp i 1 kap. $1 \S$ brottsbalken. Den bestämmelsen lyder:

\footnotetext{
Hovrättslagman i Hovrätten över Skåne och Blekinge.

** Title in English: How can we Ensure Comparable Penalties for Similar Crimes? Original in Swedish.
} 
Brott är en gärning som är beskriven $i$ denna balk eller $i$ annan lag eller författning och för vilken straff som sägs nedan är föreskrivet.

Straff som sägs nedan är böter och fängelse.

Vi tänker oss nog ibland att den svenska straffrätten är exemplarisk när det gäller beaktandet av legalitetsprincipen. Men det finns faktiskt ganska allvarliga luckor i lagstiftningen. En sådan är att det inte finns någon lagstiftning om innebörden av uppsåtsbegreppet. Inte heller har lagstiftaren tagit ställning för hur den straffrättsliga täckningsprincipen ska tillämpas i olika situationer. På dessa områden - och även på vissa andra - har det överlämnats åt domstolarna och den juridiska doktrinen att försöka klarlägga hur rättsläget ser ut. Intressant i sammanhanget är att en statlig utredning, Straffansvarsutredningen, år 1996 lade fram ett förslag som innebar att innebörden av uppsåtsbegreppet skulle lagfästas. ${ }^{2}$ Genom regeringens proposition 2000/01:85, som godtogs av riksdagen, överlämnades dock frågan om vad uppsåt är även fortsättningsvis åt domstolarna. Lagstiftarens ovilja att ta ansvar för uppsåtsregleringen är förvånande särskilt som man i ett lagstiftningsärende några år tidigare hade vidtagit åtgärder för att stärka legalitetsprincipens ställning, bl.a. genom ett uttryckligt förbud mot analogisk tillämpning av straffbestämmelser. ${ }^{3}$

Legalitetsprincipen tar primärt sikte på just frågan, vilka gärningar som är straffbara. Men den innebär också att det ska finnas klara regler om vilka påföljder som olika gärningar ska leda till. Det är ju lika viktigt att det inte sker något övergrepp mot den enskilde när påföljden bestäms som att han eller hon inte döms för gärningar som inte utgjorde brott när de begicks.

Att tillämpa legalitetsprincipen på påföljdsbestämningsområdet var enklare i äldre system. När strafflagen trädde i kraft år 1865 innehöll påföljdssystemet endast straff som böter, fängelse och straffarbete. Dessa var möjliga att mäta ut så att straffet kunde bestämmas i proportion främst till brottets allvar.

Med det påföljdssystem som vi har nu är situationen delvis annorlunda. Påföljdssystemet innehåller numera en lång rad olika påföljder och påföljdskombinationer. Noga räknat rör det sig om ca tjugofem olika påföljder eller påföljdskombinationer i det svenska systemet. Vissa av dem tillämpas i och för sig i stort sett aldrig, men det finns tillräckligt många alternativa påföljder eller påföljdskombinationer som används frekvent för att det ska uppstå problem med förutsebarheten och enhetligheten och därmed med att upprätthålla legalitetsprincipen.

Straffmätning förekommer fortfarande i ganska stor utsträckning precis som på den gamla strafflagens tid, men flera typer av påföljder går det knappast att straffmäta. Detta gäller för villkorlig dom (utan böter), skyddstillsyn (utan böter eller fängelse), ungdomsvård (utan böter eller ungdomstjänst) och rättspsykiatrisk 
vård. Samtidigt straffmäter vi i Sverige i vissa fall påföljder som vi inte vill kalla straff. ${ }^{4}$ Det rör sig om samhällstjänst, ungdomstjänst och sluten ungdomsvård.

Det är uppenbart att hanteringen av en så stor mängd påföljder av olika slag och med olika tillämpningsförutsättningar ställer stora krav på dem som ska tillämpa dem.

\section{Kan vi uppnå en enhetlig påföljdsbestämning?}

Påföljdsbestämning bygger i stor utsträckning på en domstolstradition som har utvecklat sig inom de ramar som lagstiftaren har angett. När påföljd ska bestämmas jämför man med hur man har bedömt motsvarande fall tidigare och anpassar påföljden för det nya brottet efter hur praxis ser ut. Detta är en god och nödvändig metod, som i sig verkar för en enhetlig rättstillämpning.

Det sägs ibland att inget fall är det andra likt och att vi därför inte behöver bekymra oss om en enhetlig rättstillämpning på påföljdsområdet. Dessutom skiljer ju sig gärningsmännen från varandra när det gäller ålder, tidigare brottslighet, behov av behandling, lämplighet för samhällstjänst etc.

Samtidigt står det klart att många brott är tämligen likartade. Detta gäller t.ex. en stor mängd av de rena bötesbrotten, särskilt förseelser i trafiken, men också sådana brott som grovt rattfylleri, bostadsinbrott, mened och vapenbrott. Och beträffande andra brott kan man lätt urskilja den avgörande straffvärdefaktorn och bestämma påföljden efter den. Detta gäller t.ex. narkotikabrotten.

Enligt min uppfattning kan påföljdsbestämningen beträffande en hel del brott vara tämligen schablonmässig. Det kan säkert finnas olika anledningar till att personer kör för fort, har för dåligt mönsterdjup på däcken, har låtit bli att betala vägtrafikskatt eller har kört en bil med körförbud. Men det är nog få som tycker att det behövs någon fingradering av påföljderna för dessa brott. Har man exempelvis överskridit högsta tillåtna hastighet på visst sätt så blir böterna kanske $2000 \mathrm{kr}$. oavsett de närmare omständigheterna vid förseelsen. Detta är inte kontroversiellt.

Även vid något allvarligare brottslighet kan det finnas skäl för en påföljdsbestämning av taxekaraktär. I Sverige är det allmänt accepterat att bötesstraffen för många vanliga brott såsom snatteri, bedrägligt beteende, skadegörelse, ringa narkotikabrott, olovlig körning och rattfylleri (som inte är grovt) bestäms med hänsyn till endast en eller ett par enkla parametrar såsom värdet av det tillgripna eller den skadade egendomen eller den uppmätta alkoholhalten hos föraren.

Den nu diskuterade frågan har inte bara att göra med grundläggande straffrättsliga principer. Man måste också beakta kostnaderna för hanteringen av påföljdssystemet. Ju mer differentierat påföljdssystemet är och ju fler faktorer vi vill väga in vid påföljdsbestämningen, desto mer komplicerat blir beslutsfattandet. Och blir beslutsfattandet mera komplicerat så kostar det också mer att driva ge- 
nom att det krävs en mera kompetent beslutsorganisation och ett mera invecklat förfarande.

I Sverige pågår det för närvarande en diskussion som rör frågan, om inte ytterligare fall av påföljdsbestämning kan avgöras av polisen genom utfärdande av ordningsbot eller av åklagarna genom strafföreläggande. ${ }^{5}$ Min bedömning är att det finns en ganska bred acceptans av lagföringsmetoder som innebär att domstolen inte behöver kopplas in i fall då den misstänkte erkänner brottet och saken också i övrigt är klar. I detta ligger att man accepterar principen samma bot för samma brott.

Det finns naturligtvis en gräns för hur schablonmässig man kan vara. Rör det sig om allvarligare brott, som renderar allvarligare påföljder, duger det inte med förenklade påföljdsbestämningssystem och taxebetonad påföljdsbestämning. Då krävs det att alla på saken inverkande omständigheter blir beaktade på ett seriöst sätt. Det är här som domstolsförfarandet kommer in. Och det är här som de specifika reglerna för påföljdsbestämningen ska tillämpas.

I Sverige har vi sedan år 1989 tämligen detaljerade regler för vilken hänsyn som ska tas till olika inverkande faktorer. ${ }^{6}$ Utgångspunkten är den för brottet gällande straffskalan, som anger brottets abstrakta straffvärde. Inom denna skala gäller det sedan att bestämma det aktuella brottets konkreta straffvärde. Straffvärdetänkandet bygger på idén att det ska råda proportionalitet mellan brottet och påföljden för brottet. Detta innebär i sin tur att utgångspunkten ska vara att det ska råda ekvivalens mellan påföljderna för lika svåra brott.

Utöver straffvärdet ska ett flertal andra omständigheter påverka det slutliga resultatet av påföljdsbestämningsprocessen. Det är sådant som tidigare brottslighet, billighetsskäl, den tilltalades ungdom, risken för att han eller hon fortsätter att begå brott, bedömt behandlingsbehov m.m. I Sverige har vi även en faktor som kallas "brottets art" som kan leda till en strängare påföljd än brottets straffvärde motiverar.

Påföljdsbestämning utförs av människor. Det är en komplicerad bedömning som ska göras, som dessutom innebär att även faktorer som kan vara osäkra, såsom risken för att den tilltalade fortsätter att begå brott, ska beaktas. Det säger sig själv att resultatet kan variera från gång till annan i fall som framstår som likvärdiga. Någon fullständig enhetlighet är det inte möjligt att uppnå.

Men att man inte kan nå fullständig enhetlighet vid påföljdsbestämningen för allvarligare brottslighet betyder inte att man måste eller bör ge upp försöken att döma så enhetligt som möjligt. Enligt min mening gäller det för domarna att först och främst enas om hur regelsystemets struktur ser ut och sedan att definiera de olika omständigheter som inverkar på slutresultatet och skaffa sig en gemensam uppfattning om hur dessa ska bedömas och vilken betydelse de ska få. 
Man kunde tycka att alla dessa frågor borde vara lösta i och med att vi har en lagstiftning på området. Men denna är faktiskt inte så tydlig och detaljerad att den ger tillräcklig vägledning. Ett exempel är att det i lagen anges att den tilltalades ålder ska beaktas vid påföljdsbestämningen om han eller hon inte hade fyllt 21 år när brottet begicks. Hur detta beaktande ska ske sägs det dock inget om, även om det förstås ska leda till en mildare bedömning för den unge. Därmed behövs det hjälpregler för att alla domare ska beakta åldersfaktorn på samma sätt. På motsvarande sätt behövs det hjälpregler för vilken närmare betydelse tidigare brottslighet ska ha o.s.v. Frågan blir då hur sådana hjälpregler kan skapas och hur ansvarsfördelningen bör vara mellan de olika aktörer som verkar inom påföljdsbestämningsområdet.

\section{De olika aktörerna på området}

\section{Lagstiftaren}

Den viktigaste aktören är naturligtvis lagstiftaren. Lagstiftaren anger vilka straffskalor som ska gälla för olika brott men ger också de andra bestämmelserna rörande påföljdsbestämningen. Men det finns begränsningar för hur detaljerad lagstiftaren kan vara. Lagregler ska i allmänhet tillämpas i en mängd olika situationer som det är hart när omöjligt att förutse. Lagstiftaren bör därför inte ha högre ambitioner än att bestämma de påföljder som ska tillämpas, de ramar inom vilka domstolarna ska bestämma påföljd och de olika omständigheter som ska inverka på resultatet.

I vissa fall ger lagstiftaren mera direkta anvisningar för hur domstolarna ska tillämpa reglerna än som nyss sagts. Ett klassiskt svenskt exempel är påföljdsbestämningen för värnpliktsbrott. Vid sådant brott skulle domstolarna, om situationen var en viss, först döma till villkorlig dom och, om den dömde vid nästa inkallelse vägrade värnplikt på nytt, döma till fängelse fyra månader. I en färsk svensk proposition $^{7}$, som går ut på att domstolarna ska döma strängare för våldsbrott, har lagstiftaren angett direkt hur mycket olika fängelsestraff ska skärpas. Till exempel ska den som tidigare dömdes till fängelse ett år för ett våldsbrott efter den 1 juli 2010 för motsvarande brott dömas till fängelse ett år tre månader. Som jag har förstått det finns det färska exempel även på den danska sidan på att lagstiftaren försöker detaljstyra påföljdsbestämningen. Om enhetlighet uppnås är det en god sak. Risken är bara att den möjlighet att laga efter läge som alltid måste finnas går förlorad. Och då tvingas domstolarna att döma ut påföljder som uppfattas som orättfärdiga eller att kringgå lagstiftarens anvisningar.

Slutsatsen blir att lagstiftaren bör beakta den ändamålsenliga maktfördelning som av tradition har rått mellan den lagstiftande makten och den dömande makten. 


\section{Domstolarna}

Som sagts tidigare bygger påföljdsbestämningen i stor utsträckning på en domstolstradition. Här har Högsta domstolen, men också hovrätterna, en viktig roll. Samtidigt måste det sägas att systemet för praxisbildning inte är särskilt effektivt. Högsta domstolen refererar varje år inte mer än ungefär etthundra avgöranden. År 2009 var det 93 stycken. Bara en mindre del av dessa avser brottmål. Och ytterligare färre avser påföljdsbestämning. Förra året refererades 25 brottmål som rörde frågor om ansvar eller påföljd i NJA. ${ }^{8}$ Av dessa rörde inte mer än nio specifika påföljdsfrågor, inklusive frågor om utvisning p.g.a. brott.

Ett ytterligare problem - utöver det begränsade antalet prejudikat - för rättstillämpningen är att Högsta domstolens vägledande domar kommer så slumpvis och dessutom ibland är svåra att tolka i belysningen av tidigare avgöranden. Några kommentarer till avgörandena lämnas (naturligtvis) inte heller av domstolen.

I rättsfall från hovrätterna $(\mathrm{RH})^{9}$ refereras varje år ett antal hovrättsavgöranden. År 2009 refererades 158 fall, varav 61 var mycket korta referat om utvisning på grund av brott. Ett problem med RH är att referaten inte har karaktär av prejudikat utan bara är exempel på hur hovrätterna har dömt i skilda fall. De tillmäts dock inte sällan stor betydelse av underrätterna när något motsvarande fall ska avgöras. Samtidigt gäller att det inte finns något system för kvalitetskontroll av de avgöranden som publiceras. Även sådana domar som ganska klart kan sägas avvika från den praxis som råder tas alltså med.

\section{Åklagarna}

En annan viktig funktion har åklagarna och då särskilt Riksåklagaren. Det är i Sverige Riksåklagaren som genom sina anvisningar till åklagarna bestämmer vilka bötesstraff som olika mindre allvarliga brott ska föranleda. Anvisningarna gäller primärt för utfärdande av ordningsbot, som görs av polisen, och för strafföreläggande, som utfärdas av åklagare. ${ }^{10}$ Dessa anvisningar följs dock regelmässigt också av domstolarna. Att så sker är på ett sätt naturligt genom att det bäddar för en enhetlig rättstillämpning. Det är heller knappast rimligt att den som inte vill godkänna en ordningsbot eller ett strafföreläggande och därmed får sin sak avgjord i domstol där, om han eller hon är skyldig, ska få ett annat straff än det som ordningsboten eller strafföreläggandet löd på.

\section{Parterna}

De processande parterna, och med dessa avser jag främst åklagaren och försvararen, har också ett ansvar för enhetligheten i dömandet. Det är lätt att uppfatta det så att försvararens uppgift är att se till att klienten, om han eller hon är skyldig, får en så mild påföljd som det någonsin är möjligt och åklagarens att påföljden verkligen 
ska bli kännbar. Men enligt min uppfattning har de båda professionella aktörerna också ett ansvar för rättsbildningen och för att medverka till att rättstillämpningen blir enhetlig. I vart fall åklagaren bör väl ha ett sådant ansvar?

En viktig del av rättegången blir med detta synsätt pläderingen. Då kan åklagaren och försvararen åberopa uttalanden i lagförarbeten, rättsfall och vad doktrinen säger för att säkerställa att domstolen har ett gott underlag för sin bedömning. Men det är också viktigt att rätt avgöranden överklagas till hovrätt och Högsta domstolen och att argumentationen i överklagandena är fullödig. Med rätt avgöranden menar jag naturligtvis mål i vilka det finns intressanta prejudikatfrågor. Med det system som vi har för prejudikatbildning är vi faktiskt helt beroende av att parterna förstår vilka domar som bör överklagas.

\section{Akademin}

Den juridiska doktrinen har av tradition legat ganska lågt när det gäller påföljdsbestämning. På senare år har dock intresset vuxit och ämnet har tilldragit sig ökad uppmärksamhet i undervisningen. Det är en god utveckling. Ett problem för de juridiska fakulteterna är dock fortfarande detta att påföljdsbestämningen i så hög grad bygger på en domstolstradition. Det är uppenbarligen inte lätt för den som inte följer praxis mycket noggrant att få tillräckliga kunskaper om ämnesområdet.

Det förekommer självfallet att man från akademiskt håll kommenterar olika avgöranden beträffande påföljdsbestämning. Om man använder modern informationsteknik kan kommentarerna nå ut relativt snabbt. Uppsatser och artiklar i tryckt form brukar dock i Sverige dröja ungefär ett halvår innan de kommer. Och under den tiden hinner många dömas till en påföljd som kanske skiljer sig från den som han eller hon hade fått om domaren hade haft tillgång till rättsfallskommentaren.

I detta sammanhang kan det finnas anledning att nämna även den ganska nystartade svenska Domstolsakademin. Ursprungligen vände den sig endast till nyutnämnda domare men numera har den hand om all central utbildning av domare. Påföljdsbestämning är självfallet ett av ämnena på Domstolsakademin. Även om utvecklingen inte har nått dit än kan man väl tänka sig att det inom ramen för Domstolsakademin i framtiden kan bedrivas verksamhet som mera specifikt syftar till att uppnå en större enhetlighet i påföljdsbestämningen.

\section{Hur långt har vi nått $\mathrm{i}$ dag?}

För inte så många år sedan tillämpade de svenska domstolarna flera, inbördes $\mathrm{i}$ vissa delar olika, tabeller vid bedömandet av straffvärdet av narkotikabrott eller narkotikasmuggling. Det var "chefsrådmännens listor"11, det var "Sterzel"12 och 
det var tabeller som hade tagits fram vid olika tingsrätter ${ }^{13}$. Vissa domare följde vissa listor medan andra domare tillämpade andra tabeller. Även om listorna och tabellerna var ganska lika kunde det i vissa lägen skilja en hel del. ${ }^{14}$ Numera har domarkåren enats sig om gemensamma tabeller, som har tagits in i boken Studier rörande påföljdspraxis m.m. ${ }^{15}$

Även på andra områden måste man säga att situationen har förbättrats under senare år. En tidigare verksamhet med nationella påföljdsseminarier har återupptagits och praxisdiskussioner förekommer numera på ganska många svenska domstolar, även om det inte sker på alla. Domstolsakademins seminarier, två eller tre om året, är fulltecknade vilket tyder på att intresset är stort inom domarkåren.

Däremot kan det knappast sägas att Högsta domstolen har ägnat ett ökat intresse åt påföljdsbestämningsfrågor. Det är fortfarande ganska få fall som tas upp. Ett talande exempel är att Högsta domstolen först år 2008 tog upp och behandlade hur straffmätning av flerfaldig brottslighet ska ske. ${ }^{16}$ Problemet lär ha funnits ända sedan Högsta domstolen började sin verksamhet år 1789.

Hur långt vi har nått vet vi faktiskt inte. Några vetenskapliga undersökningar som mera generellt tar sikte på problematiken har mig veterligen inte gjorts. Det är synd, för ämnet är både viktigt och intressant. Om man tänker närmare efter är det också egendomligt att det inte förekommer någon uppföljning av domstolarnas verksamhet kvalitetsmässigt. Visserligen är det viktigt att domstolarnas och domarnas självständighet i den dömande uppgiften bibehålls och värnas. Men utesluter självständigheten att verksamheten i efterhand följs upp och utvärderas? Jag har svårt att se det. Samma inställning, dvs. att en kvalitetsuppföljning bör ske, har nyss redovisats i ett svenskt utredningsbetänkande avseende förtroendet för domstolarna. ${ }^{17}$ Såvitt jag förstår har utvärderingsprojekt bedrivits både i Danmark och i Finland. ${ }^{18}$

Sammanfattningsvis är bilden den att enhetligheten nog är hygglig men att mycket mera borde kunna göras i syfte att förbättra legalitetsprincipens ställning på påföljdsbestämningsområdet.

\section{Hur går vi vidare?}

Påföljdsbestämningen kan aldrig bli hundraprocentigt enhetlig om vi i rimlig utsträckning ska beakta alla de skilda faktorer som påverkar hur allvarligt vi bör se på ett visst brott och också ta hänsyn till de olika omständigheter med anknytning till den tilltalades person som gör sig gällande. Men vi kan säkerligen nå mycket längre än vi har gjort $\mathrm{i}$ dag.

När det gäller komplicerad samhällelig verksamhet finns det sällan någon universalmedicin som löser alla problem i ett slag. Man får tänka sig att gå fram längs olika vägar. Här är några som kan diskuteras. 
Lagstiftaren bör se till att lagstiftningen är up to date. I det ligger att lagstiftaren bör följa tillämpningen av lagstiftningen och göra de justeringar som behövs. Man kan nämligen inte räkna med att $\mathrm{i}$ vart fall större lagstiftningsprojekt alltid $\mathrm{i}$ alla delar blir perfekta. Men detaljstyrning bör lagstiftaren undvika.

Högsta domstolen borde kunna åstadkomma fler prejudikat. Brottmål är en masshantering i våra domstolar och påföljdssystemet ska alltid hanteras när någon har befunnits skyldig. Frågan är alltså viktig för många. Den är också viktig när det gäller upprätthållandet av domstolarnas anseende. Är det för att påföljder huvudsakligen drabbar personer med svaga röstresurser som frågan inte på alla håll tas fullt ut på det allvar som den förtjänar? Jag vill inte tro att det förhåller sig så, men tanken har slagit mig att hade frågan rört samhällets toppar eller kanske bara "vanligt folk" hade det möjligen funnits ett större intresse.

Högsta domstolens vägledande avgöranden borde snabbare kunna diskuteras och kommenteras i medier som de professionella aktörerna på området har tillgång till.

Alla domstolar borde ägna sig åt praxisdiskussioner. Med praxisdiskussioner menar jag väl förberedda och underbyggda diskussioner mellan domare om hur man - mot bakgrund av lagstiftningen, förarbetena, Högsta domstolens domar, uttalanden i doktrinen m.m. - bör döma i olika fall. Sådana praxisdiskussioner bör hållas både lokalt, regionalt och på nationell nivå. Resultaten av diskussionerna bör spridas även utanför domstolarna.

En viktig sak är också att domstolar på alla nivåer bör anstränga sig för att främja prejudikatbildningen. Det finns en tendens att domstolarna i sina domar är ganska utförliga om sådant som de är säkra på medan de skriver betydligt mera kortfattat när det gäller frågor som de är osäkra på. Det borde vara tvärt om. Är rättsfrågorna klara kan domstolen ofta vara kortfattad medan det är en klar fördel om domstolen lägger ut texten i de delar där det kan förekomma delade meningar om innebörden av gällande rätt.

Det bör skapas uthålliga och effektiva system för framtagande av praxissammanställningar på nationell nivå. Som det nu är finns det i Sverige boken Studier rörande påföljdspraxis m.m. ${ }^{19}$ Den används allmänt i domstolarna, på åklagarkamrarna och av försvarsadvokaterna. Men den är resultatet av en liten krets personers arbete och åsikter. Frågan är om inte processen för framtagande av boken borde breddas.

Frågan om datorstöd vid påföljdsbestämning bör diskuteras. Säger man sentencing guidelines är det många som reagerar. Men innan vi har gjort ett seriöst försök att pröva denna typ av hjälpmedel är det nog oklokt att förkasta dem. Jag tror mig veta att det hos både polis och åklagare finns datorbaserade stödsystem vid utfärdande av ordningsbot och strafföreläggande. Då vore det inte konstigt om det fanns något motsvarande hos domstolarna. 
RH:s utformning och funktion som hjälpmedel vid rättstillämpningen bör diskuteras förutsättningslöst.

\section{Slutord}

Det finns mycket att ta upp inom ramen för ämnet påföljdsbestämning. En viktig fråga är naturligtvis hur sträng påföljdsbestämningen behöver vara. En annan är om det finns underliggande strömmar som påverkar domstolarna till att under vissa perioder döma förhållandevis milt men att $\mathrm{i}$ andra perioder vara påtagligt strängare. I det sammanhanget är det naturligtvis intressant att följa upp hur påföljdsbestämningen har varierat under åren och vad variationerna har berott på.

Jag har fokuserat på frågan om enhetlighet i påföljdsbestämningen. Det är en fråga som är viktig, inte minst för dem som döms till påföljd. Det är ett rimligt krav att den enskilde i förväg ska kunna bedöma vilken påföljden kommer att bli och alltså att kunna kontrollera om beslutet om påföljd är riktigt. Hur vi åstadkommer en bättre ordning kan diskuteras. Jag har lämnat vissa förslag. Självfallet är jag tacksam för fler förslag och för respons på mina. Min förhoppning är att tillräckligt många vill delta i den här diskussionen.

\section{Notes:}

Feuerbach levde 1775-1833.

2 Se SOU 1996:185 Straffansvarets gränser. Ett motsvarande förslag, dock med annan innebörd, hade tidigare lagts fram av Strafflagskommissionen i SOU 1923:9.

3 Se prop. 1993/94:130.

4 Definitionsmässigt är böter, fängelse, villkorlig dom, skyddstillsyn, ungdomsvård, ungdomstjänst, sluten ungdomsvård, överlämnande till missbruksvård och överlämnande till rättspsykiatrisk vård påföljder. Det är dock bara böter och fängelse som kallas för straff.

5 Se Redovisning i maj 2010 av ett regeringsuppdrag till Rikspolisstyrelsen, Åklagarmyndigheten och Domstolsverket.

6 Reglerna finns i 29 och 30 kap. brottsbalken.

7 Proposition 2009/10:147.

8 NJA är en förkortning av Nytt Juridiskt Arkiv, som innehåller bl.a. referat av Högsta domstolens vägledande avgöranden.

9 En publikation som för närvarande redigeras av en hovrättslagman i Hovrätten för Västra Sverige och som ges ut av Domstolsverket.

10 Anvisningarna för ordningsbot finns i SFS 1999:178 och anvisningarna för strafföreläggande i bl.a. i RåR 2007:2, RÅPM 2003:2 och RättsPM 2006:23.

11 En överenskommelse mellan chefsrådmännen vid Stockholms tingsrätt, Göteborgs tingsrätt och Malmö tingsrätt om straffvärdebedömningen av narkotikabrott.

12 Georg Sterzel, Studier rörande påföljdspraxis m.m. första upplagan 1998 och andra upplagan 2000.

13 T.ex. Helsingborgs tingsrätt och Trelleborgs tingsrätt.

14 I ett fall innebar chefsrådmännens lista att påföljden skulle bli fängelse fyra år medan en tillämpning av "Sterzel" skulle leda till fängelse tre år sex månader. 
15 Georg Sterzel-Martin Borgeke, Studier rörande påföljdspraxis m.m. tredje upplagan 2005 och Martin Borgeke-Georg Sterzel, Studier rörande påföljdspraxis m.m. fjärde upplagan 2009.

16 Se den s.k. Skärtorsdagsdomen, NJA 2008 s. 359.

17 Ökat förtroende för domstolarna - strategier och förslag (SOU 2008:106) s. 202 ff.

18 För Danmarks del kan hänvisas till Rapporten Dokumentation og målning af kvalitet ved domstolene (2005) och för Finlands rapporten Bedömning av kvaliteten på rättskipningen i domstolarna - Utgångspunkter och mätare (2006).

19 Tidigare kallad "Sterzel".

Adresse:

Hovrätten over Skåne och Blekinge

Box 846

20180 MALMÖ

040/35 5750

0709-70 7786

martin.borgeke@dom.se 